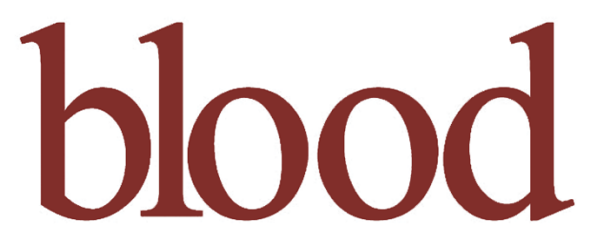

2004 104: 1258-1265

Prepublished online May 4, 2004;

doi:10.1182/blood-2003-12-4434

\title{
Follicular Lymphoma International Prognostic Index
}

Philippe Solal-Céligny, Pascal Roy, Philippe Colombat, Josephine White, Jim O. Armitage, Reyes Arranz-Saez, Wing Y. Au, Monica Bellei, Pauline Brice, Dolores Caballero, Bertrand Coiffier, Eulogio Conde-Garcia, Chantal Doyen, Massimo Federico, Richard I. Fisher, Javier F. Garcia-Conde, Cesare Guglielmi, Anton Hagenbeek, Corinne Haïoun, Michael LeBlanc, Andrew T. Lister, Armando Lopez-Guillermo, Peter McLaughlin, Noël Milpied, Pierre Morel, Nicolas Mounier, Stephen J. Proctor, Ama Rohatiner, Paul Smith, Pierre Soubeyran, Hervé Tilly, Umberto Vitolo, Pier-Luigi Zinzani, Emanuele Zucca and Emili Montserrat

Updated information and services can be found at:

http://bloodjournal.hematologylibrary.org/content/104/5/1258.full.html

Articles on similar topics can be found in the following Blood collections

Clinical Trials and Observations (3447 articles)

Free Research Articles (1356 articles)

Neoplasia (4217 articles)

Information about reproducing this article in parts or in its entirety may be found online at:

http://bloodjournal.hematologylibrary.org/site/misc/rights.xhtml\#repub_requests

Information about ordering reprints may be found online at:

http://bloodjournal.hematologylibrary.org/site/misc/rights.xhtml\#reprints

Information about subscriptions and ASH membership may be found online at:

http://bloodjournal.hematologylibrary.org/site/subscriptions/index.xhtml

Blood (print ISSN 0006-4971, online ISSN 1528-0020), is published weekly by the American Society of Hematology, 2021 L St, NW, Suite 900, Washington DC 20036.

Copyright 2011 by The American Society of Hematology; all rights reserved.

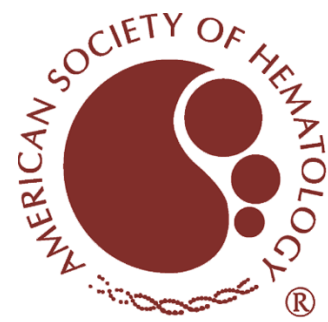




\section{Follicular Lymphoma International Prognostic Index}

Philippe Solal-Céligny, Pascal Roy, Philippe Colombat, Josephine White, Jim O. Armitage, Reyes Arranz-Saez, Wing Y. Au, Monica Bellei, Pauline Brice, Dolores Caballero, Bertrand Coiffier, Eulogio Conde-Garcia, Chantal Doyen, Massimo Federico, Richard I. Fisher, Javier F. Garcia-Conde, Cesare Guglielmi, Anton Hagenbeek, Corinne Haïoun, Michael LeBlanc, Andrew T. Lister, Armando Lopez-Guillermo, Peter McLaughlin, Noël Milpied, Pierre Morel, Nicolas Mounier, Stephen J. Proctor, Ama Rohatiner, Paul Smith, Pierre Soubeyran, Hervé Tilly, Umberto Vitolo, Pier-Luigi Zinzani, Emanuele Zucca, and Emili Montserrat

The prognosis of follicular lymphomas $(F L)$ is heterogeneous and numerous treatments may be proposed. A validated prognostic index (PI) would help in evaluating and choosing these treatments. Characteristics at diagnosis were collected from 4167 patients with FL diagnosed between 1985 and 1992. Univariate and multivariate analyses were used to propose a PI. This index was then tested on 919 patients. Five adverse prognostic factors were selected: age ( $>60$ years vs $\leq 60$ years), Ann Arbor stage (III-IV vs I-II), hemoglobin level $(<120 \mathrm{~g} / \mathrm{L}$ vs $\geq 120$ $\mathrm{g} / \mathrm{L}$ ), number of nodal areas ( $>4$ vs $\leq 4$ ), and serum LDH level (above normal vs normal or below). Three risk groups were defined: low risk (0-1 adverse factor, $36 \%$ of patients), intermediate risk (2 factors, $37 \%$ of patients, hazard ratio [HR] of 2.3 ), and poor risk ( $\geq 3$ adverse factors, $27 \%$ of patients, HR = 4.3). This Follicular Lymphoma International Prognostic Index (FLIPI) appeared more discriminant than the International Prognostic Index proposed for aggressive non-Hodgkin lymphomas. Results were very similar in the confirmation group. The FLIPI may be used for improving treatment choices, comparing clinical trials, and designing studies to evaluate new treatments. (Blood. 2004;104:1258-1265)

() 2004 by The American Society of Hematology

\section{Introduction}

Follicular lymphomas (FLs) account for one third of nonHodgkin lymphomas (NHLs) in adults. The course of the disease is usually characterized by a response to initial treatment, followed by relapses, sometimes associated with histologic transformation into high-grade NHL. ${ }^{1}$ From "watchful waiting" to high-dose therapy, numerous treatment options have been proposed for patients with FL. Meanwhile, there is no consensus on any of these approaches. Agreement in the treatment algorithm of patients with FL would be made easier by a simple, validated, and accurate prognostic index similar to the International Prognostic Index proposed for aggressive NHLs in $1993 .^{2}$ In retrospective analyses of a series of FL or indolent NHLs, several characteristics were associated with a poor clinical outcome such as advanced age, ${ }^{3-10}$ male sex, ${ }^{4,7,11,12}$ disseminated disease according to Ann Arbor classification, ${ }^{1,4}$ high number of nodal ${ }^{3,7}$ and/or extra nodal involvement sites, ${ }^{12}$ presence of bulky tumor(s), ${ }^{6,8}$ increased serum lactate dehydrogenase $(\mathrm{LDH})^{13}$ and/or $\beta_{2}$ microglobulin ${ }^{14}$ levels, poor performance status, ${ }^{5,6}$ and a low hemoglobin level. ${ }^{4}$ From these analyses, a few prognostic indices have been proposed ${ }^{3,4,9,12}$ but none of them has been validated and/or widely used. Several retrospective analyses have also suggested that the International Prognostic Index (IPI) initially designed for aggressive NHLs could also be used in indolent NHLs. ${ }^{15-20}$ However, some important prognostic factors may have been missed since the IPI was not designed to investigate prognostic factors in FL. Moreover, when using the IPI, very few patients (around 10\%-15\%) with FL are classified in the poor-risk category. Because of this, the IPI is not appropriate to identify patients in whom intensive therapy has to be tested. An international cooperative study was thus designed to collect the data on initial characteristics of a large number of patients with FL and to propose a prognostic index for FL. This
From the Centre J. Bernard, Le Mans, France; Service de Biostatistiques, Lyon, France; Groupe d'Etudes Ouest-Est des Leucemies Aiguës et Autres Maladies du Sang, Tours, France; Medical Statistics Unit, Edinburgh, United Kingdom; Nebraska Lymphoma Study Group, Omaha; LNH Pro Study Group, Madrid, Spain; Intergruppo Italiano Linfomi, Modena, Italy; Groupe d'Etude des Lymphomes de l'Adulte, Creteil, France; H.U. Marques de Valdecilla, Santander, Spain; Universitario de Salamanca, Spain; Hôpital Universitaire de Mont-Godinne, Belgium; SouthWest Oncology Group; Hospital Clinico Universitario, Valencia, Spain; Hôpital Hotel-Dieu, Nantes, France; Universita La Sapienza, Roma, Italy; European Organization for Research and Treatment of Cancer, Brussels, Belgium; Hôpital Henri Mondor, Créteil, France; Hôpital Saint-Louis, Paris, France; Saint Bartholomew's Hospital, London, United Kingdom; British National Lymphoma Intergroup, London, United Kingdom; Grup per l'Estudi dels Limfomes de Catalunya I Balears, Barcelona, Spain; MD Anderson Cancer Center, Houston, TX; Centre Hospitalier Universitaire (CHU) L. Huriez, Lille, France; Institut Bergonié, Bordeaux, France; Scotland and Newcastle Lymphoma Study Group, Edinburgh, United Kingdom; Centre Henri Becquerel, Rouen, France; Queen Mary Hospital, Hong Kong, China; and Ospedale San-Giovanni, Bellinzona, Switzerland.
Submitted January 8, 2004; accepted March 17, 2004. Prepublished online as Blood First Edition Paper, May 4, 2004; DOI 10.1182/blood-2003-12-4434.

Supported by the Ministry of Health (France), the Ministry of Health and Research (Spain), the Groupe d'Etude des Lymphomes de l'Adulte (France and Belgium), the Groupe Ouest-Est des Leucémies Aiguës et Autres Maladies du Sang (France), the Nebraska Lymphoma Study Group, Cancer Research Switzerland grant KFS 00792-2-1999, and the following pharmaceutical companies, in alphabetical order: Amgen France (Neuilly-sur-Seine, France), Idec Pharmaceuticals (San Diego, CA), Produits Roche (Neuilly-sur-Seine, France), Schering AG (Lyz-les-Lannoy, France, and Madrid, Spain), and Schering-Plough (Kennilworth, NJ).

An Inside Blood analysis of this article appears in the front of this issue.

Reprints: Philippe Solal-Celigny, Centre Jean-Bernard, 9 rue Beauverger, 72000 Le Mans, France; e-mail: p.solal-celigny@noos.fr.

The publication costs of this article were defrayed in part by page charge payment. Therefore, and solely to indicate this fact, this article is hereby marked "advertisement" in accordance with 18 U.S.C. section 1734.

(c) 2004 by The American Society of Hematology 
cooperative study culminated in a proposal for a Follicular Lymphoma International Prognostic Index (FLIPI).

\section{Patients and methods}

\section{Patients}

The following inclusion criteria were used: (1) Follicular lymphoma according to the Working Formulation for Clinical Usage ${ }^{21}$ and/or the Kiel classification, ${ }^{22}$ which were in use at the time of the period of inclusion. All cell types (small-cell, mixed, or large-cell FL) could be included in the study. No central pathology review was performed. (2) Initial diagnosis between January 1, 1985, and December 31, 1992. (3) Staging procedures including at least a CT scan of the thorax, abdomen and pelvis, or lymphangiography plus abdominal and pelvis echography, bone marrow biopsy, routine blood counts, and biochemistry tests. (4) Follow-up until death, or for at least 5 years for surviving patients. The FLIPI was a retrospective study that relied on patients included in several trials conducted according to legal guidelines in each country at the time of study. Consent for this study was part of the informed consent given for these trials. The study was approved by the French Committee for the Use of Computerized Medical Data.

\section{Data collection}

Demographic characteristics and initial staging. Nodal areas considered were cervical, axillary, inguino-crural, para aortic and/or iliac, celiac and/or mesenteric, and other ancillary nodal sites. Involved area (or areas) either clinically or on CT scan (or scans) was quoted as 1 (2 if bilateral) and each patient had between 0 and 8 or more involved areas (Figure 1). All extra nodal areas were taken into account. In the absence of any agreement on a threshold, it was not possible to define a bulky tumor. As in the International Prognostic Index for aggressive NHLs ${ }^{2}$ the spleen was considered as an extra nodal site.

Clinical and biologic characteristics. The following clinical and biologic characteristics were related to disease extension and/or tumor bulk: cell type, Ann Arbor stage, serum LDH, and $\beta_{2}$ microglobulin levels (expressed as the ratio of the measured value to the upper limit of normal for the center). The following clinical and biologic characteristics were related to the effects of FL on the host: performance status according to the

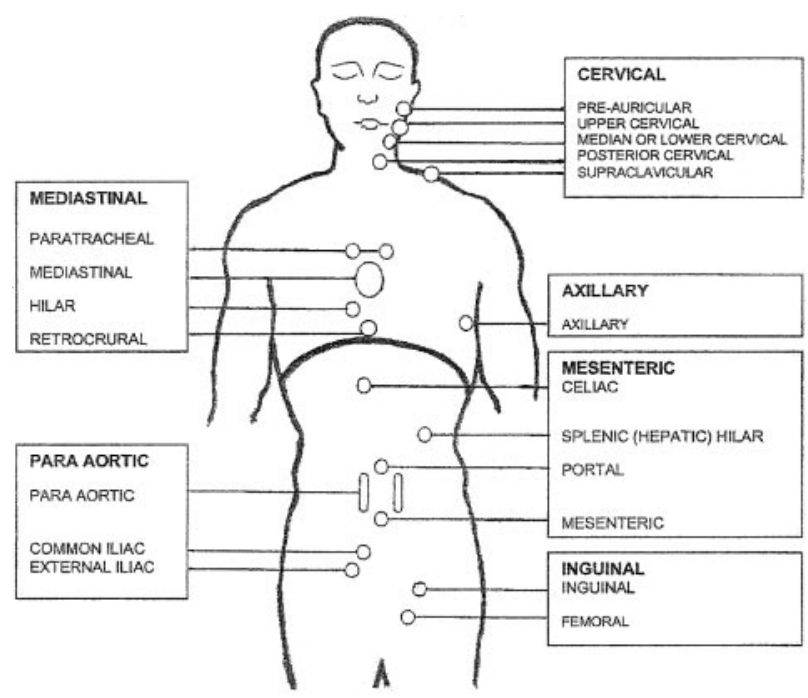

OTHERS : EPITROCHLEAR, POPLITEAL

Figure 1. Mannikin used for counting the number of involved areas. See "Demographic characteristics and initial staging" in the text. Each rectangle corresponds to a nodal area.
Table 1. Accrual of patients in the FLIPI study

\begin{tabular}{lclr}
\hline & $\begin{array}{c}\text { Group (G) or } \\
\text { center (C) }\end{array}$ & $\begin{array}{c}\text { Country or } \\
\text { countries }\end{array}$ & $\begin{array}{r}\text { No. of } \\
\text { patients }\end{array}$ \\
\hline Barcelona & G & Spain & 142 \\
Becquerel H Hospital & C & France & 127 \\
Bellinzona & C & Switzerland & 60 \\
Bergamo Hospital & C & Italy & 42 \\
Bergonié Institute & C & France & 65 \\
BNLI & G & United Kingdom & 474 \\
Bretonneau Hospital & C & France & 35 \\
EORTC & G & Europe & 347 \\
GELF & G & France, Belgium & 567 \\
GOELAMS & G & France & 118 \\
Hotel Dieu Nantes Hospital & C & France & 42 \\
Huriez L Hospital & C & France & 87 \\
Intergruppo Italiano Linfomi & G & Italy & 848 \\
\hline LNH-Pro & G & Spain & 55 \\
Lyon-Sud & C & France & 197 \\
MD Anderson & C & United States & 451 \\
Mondor H Hospital & C & France & 34 \\
Mont-Godinne Hospital & C & Belgium & 27 \\
Nebraska Lymphoma Study Group & C & United States & 186 \\
Queen Mary Hospital Hong Kong & C & China & 66 \\
Saint Bartholomew Hospital & C & United Kingdom & 108 \\
Saint Louis Hospital & C & France & 33 \\
Salamanca Hospital & C & Spain & 18 \\
Santander Hospital & C & Spain & 57 \\
Sapienza (La) Roma & C & Italy & 94 \\
SNLG & G & United Kingdom & 557 \\
SWOG & G & United States & 283 \\
\hline & & & \\
\hline
\end{tabular}

Data are organized alphabetically by center. BNLI indicates British National Lymphoma Intergroup; EORTC, European Organization for the Treatment of Cancer GELF, Groupe d'Etude des Lymphomes Folliculaires; GOELAMS, Groupe Ouest-Est des Leucémies Aiguës et Autres Maladies du Sang; SNLG, Scotland and Newcastle Lymphoma Study Group; and SWOG, SouthWest Oncology Group.

Eastern Cooperative Oncology Group scale, presence or absence of any B symptoms, anemia, lymphocytopenia, decreased serum albumin level, increased erythrocyte sedimentation rate (ESR), thrombocytopenia.

\section{Statistical analysis}

Overall survival was the end point of all statistical analyses. Survival rates and corresponding standard errors were estimated using Kaplan and Meier

Overall Survival $(\mathrm{n}=\mathbf{4 1 6 7})$

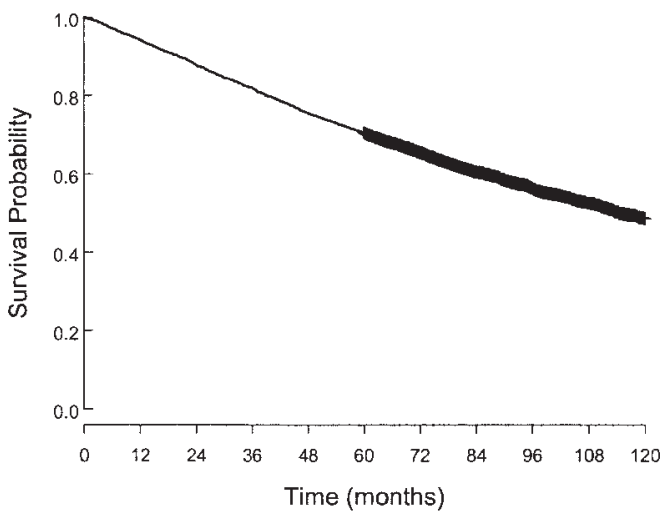

$\begin{array}{llllllllllll}\text { No. of Events } & - & 237 & 507 & 747 & 1017 & 1226 & 1418 & 1569 & 1671 & 1737 & 1786\end{array}$ $\begin{array}{llllllllllll}\text { No. at Risk } \quad 4167 & 3930 & 3660 & 3420 & 3150 & 2939 & 2232 & 1630 & 1163 & 778 & 479\end{array}$

Figure 2. Overall survival of the study population $(n=4167)$. 
estimators. ${ }^{23}$ Survival curves were compared applying the log-rank test. Continuous biologic variables were dichotomized applying usual clinical thresholds. These a priori chosen thresholds were checked using cubic smoothing spline ${ }^{24}$ and the risk function of a proportional hazard model. ${ }^{25} \mathrm{~A}$ prognostic model was built fitting a proportional hazard model with all variables that significantly influenced the overall survival at a level of $P$ values less than or equal to .05 in the univariate analysis (full model). A forward stepwise Cox regression analysis ${ }^{25}$ was then performed, including age and sex and, successively, extent of the disease, influence of the disease on the host, and other biologic variables. The prognostic index was derived from the prognostic model resulting from the Cox analysis. The clinical committee of the project asked for an index that would include no more than 5 variables in order to make its use easier in routine practice. If the Cox analysis retained more than 5 variables, it was decided to select the 5 variables from the prognostic model that produced the smallest loss of discriminating power. For choosing the most accurate model, all the

Table 2. Characteristics of the patients and results of the univariate analysis of prognostic factors

\begin{tabular}{|c|c|c|c|c|c|}
\hline Parameter & $\mathbf{n}$ & $\%$ & $\begin{array}{c}\text { 5-year survival, } \\
\% \text { (SE) }\end{array}$ & $\begin{array}{c}\text { 10-year survival, } \\
\% \text { (SE) }\end{array}$ & $\begin{array}{c}\log \text { rank, } \\
P\end{array}$ \\
\hline Sex & 4167 & & & & .0025 \\
\hline Female & & 49 & $72.5(1.0)$ & $51.0(1.4)$ & \\
\hline Male & & 51 & $68.7(1.0)$ & $46.2(1.4)$ & \\
\hline Age & 4167 & & & & $<10^{-4}$ \\
\hline Younger than $60 \mathrm{y}$ & & 63 & $78.1(0.8)$ & $58.4(1.2)$ & \\
\hline 60 y or older & & 37 & $57.7(1.3)$ & $32.3(1.6)$ & \\
\hline Cell type & 3511 & & & & .1065 \\
\hline Small cell & & 50 & $71.8(1.1)$ & $48.6(1.5)$ & \\
\hline Mixed & & 41 & $71.1(1.2)$ & $50.4(1.7)$ & \\
\hline Large cell & & 9 & $66.1(2.7)$ & $40.0(3.9)$ & \\
\hline Ann Arbor stage & 4162 & & & & $<10^{-4}$ \\
\hline $\mid-I I$ & & 22 & $83.2(1.2)$ & $64.3(2.0)$ & \\
\hline III-IV & & 78 & $67.0(0.8)$ & $44.1(1.1)$ & \\
\hline B symptoms & 3965 & & & & $<10^{-4}$ \\
\hline Absence & & 81 & $73.8(0.8)$ & $50.7(1.2)$ & \\
\hline Presence & & 19 & $55.8(1.8)$ & $36.8(2.3)$ & \\
\hline Performance status (ECOG) & 3602 & & & & $<10^{-4}$ \\
\hline $0-1$ & & 88 & $72.4(0.8)$ & $50.0(1.2)$ & \\
\hline More than 1 & & 12 & $58.6(2.4)$ & $37.8(3.0)$ & \\
\hline Number of nodal sites & 3322 & & & & $<10^{-4}$ \\
\hline $0-4$ & & 65 & $77.0(0.9)$ & $54.6(1.4)$ & \\
\hline 5 or more & & 35 & $63.7(1.4)$ & $42.1(1.9)$ & \\
\hline Number of extra nodal sites other than bone marrow & 3741 & & & & $<10^{-4}$ \\
\hline 0 & & 62 & $76.1(0.9)$ & $55.4(1.3)$ & \\
\hline 1 or more & & 38 & $63.7(1.3)$ & $40.8(1.7)$ & \\
\hline Bone marrow involvement & 4016 & & & & $<10^{-4}$ \\
\hline Absence & & 52 & $75.6(0.9)$ & $56.2(1.3)$ & \\
\hline Presence & & 48 & $65.7(1.1)$ & $40.4(1.6)$ & \\
\hline Spleen involvement & 3816 & & & & $<10^{-4}$ \\
\hline Absence & & 78 & $74.8(0.8)$ & $53.0(1.2)$ & \\
\hline Presence & & 22 & $57.6(1.7)$ & $36.5(2.1)$ & \\
\hline Serum $\beta_{2}$ microglobulin & 716 & & & & $<10^{-4}$ \\
\hline Less than or equal to ULN & & 59 & $86.0(1.7)$ & $65.1(3.9)$ & \\
\hline Greater than ULN & & 41 & $65.0(2.8)$ & $42.5(3.8)$ & \\
\hline ESR & 2256 & & & & $<10^{-4}$ \\
\hline Less than or equal to $40 \mathrm{~mm} / \mathrm{h}$ & & 89 & $73.3(1.0)$ & $52.0(1.4)$ & \\
\hline Greater than $40 \mathrm{~mm} / \mathrm{h}$ & & 11 & $43.6(3.2)$ & $28.5(3.6)$ & \\
\hline Serum LDH & 2565 & & & & $<10^{-4}$ \\
\hline Less than or equal to ULN & & 79 & $76.6(0.9)$ & $53.9(1.6)$ & \\
\hline Greater than ULN & & 21 & $57.6(2.1)$ & $41.4(2.7)$ & \\
\hline Thrombocyte count & 3655 & & & & $<10^{-4}$ \\
\hline Greater than or equal to $150 \times 10^{9} / \mathrm{L}$ & & 88 & $72.2(0.8)$ & $50.5(1.2)$ & \\
\hline Less than $150 \times 10^{9} / \mathrm{L}$ & & 12 & $59.9(2.3)$ & $36.1(3.1)$ & \\
\hline Hemoglobin level & 3813 & & & & $<10^{-4}$ \\
\hline Greater than or equal to $120 \mathrm{~g} / \mathrm{L}$ & & 82 & $74.9(0.8)$ & $51.7(1.2)$ & \\
\hline Less than $120 \mathrm{~g} / \mathrm{L}$ & & 18 & $50.7(1.9)$ & $35.0(2.3)$ & \\
\hline PB lymphocyte count & 3122 & & & & $<10^{-4}$ \\
\hline Greater than or equal to $1 \times 10^{9} / \mathrm{L}^{*}$ & & 80 & $73.3(0.9)$ & $51.5(1.3)$ & \\
\hline Less than $1 \times 10^{9} / \mathrm{L}$ & & 20 & $62.5(2.0)$ & $39.2(2.6)$ & \\
\hline Serum albumin level & 2116 & & & & $<10^{-4}$ \\
\hline Greater than or equal to $35 \mathrm{~g} / \mathrm{L}$ & & 90 & $72.3(1.0)$ & $50.3(1.4)$ & \\
\hline Less than $35 \mathrm{~g} / \mathrm{L}$ & & 10 & $48.3(3.5)$ & $25.8(4.0)$ & \\
\hline
\end{tabular}

SE indicates standard error; ESR, erythrocyte sedimentation rate; LDH, lactate dehydrogenase; ULN, upper limit of normal; PB, peripheral blood; and ECOG, Eastern Cooperative Oncology Group.

*Patients with leukemic involvement were not separated because blood involvement was considered an extra nodal site. 


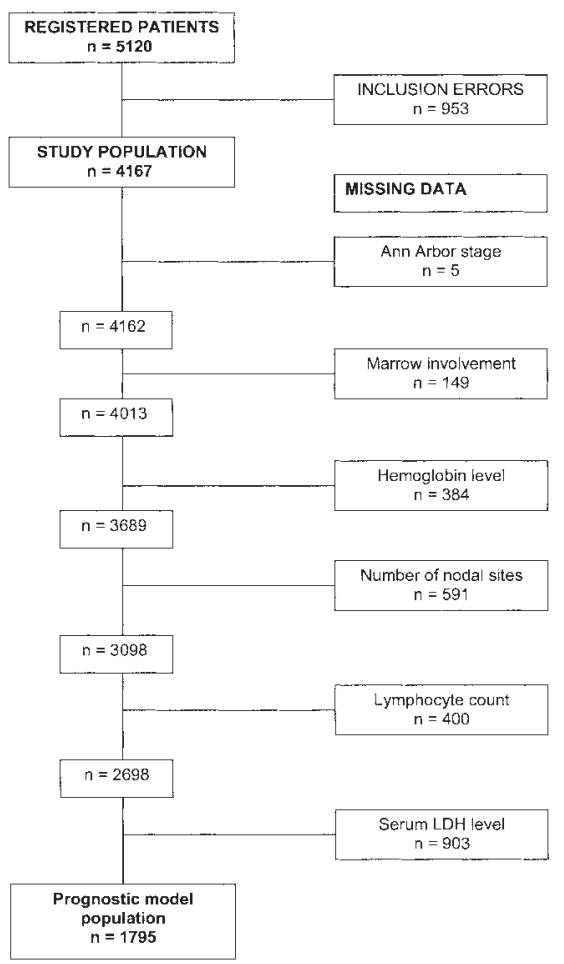

Figure 3. Numbers of patients included for designing the FLIPI. From the study population, the remaining number of patients who had information on the 8 significan factors after Cox analysis are mentioned. Note that no data were missing for age and sex.

candidates with 4 variable models other than age were classified according to 2 criteria: (1) score tests, evaluated on 100 resamples of the original data set; and (2) the Somer D coefficient adapted from Harrell et $\mathrm{a}^{26}$ for measuring concordance of observed and expected survival, with correction of optimism using the bootstrap technique. Risk groups were defined by comparing the relative risk of death in patients with each possible number of presenting risk factors (from 0 to 5). Then, categories were combined according to the number of patients within each category, the combination producing the smallest loss of information in terms of $\log$ likelihood, and clinical consideration in order to obtain 3 categories of approximately equal size.

\section{External validation}

Inclusion criteria for external validation were similar to those of the initial study, with 2 specificities: diagnosis after January 1993, and availability of the information on the 5 parameters of the FLIPI.

Table 3. Results of the Cox regression analysis in 1795 patients who exhibited the 8 parameters having significant influence on overall survival

\begin{tabular}{llccc}
\hline \multicolumn{1}{c}{ Variable } & Adverse factor & $\boldsymbol{P}$ & RR & $\mathbf{9 5 \%} \mathbf{~ C l}$ \\
\hline Sex & Male & .001 & 1.33 & $1.14-1.56$ \\
Age & $>60$ years & $<10^{-3}$ & 2.40 & $2.05-2.81$ \\
Ann Arbor stage & III-IV & $<10^{-3}$ & 1.66 & $1.26-2.19$ \\
Bone marrow & Involved & .001 & 1.37 & $1.14-1.64$ \\
Number of nodal sites & $>4$ & .001 & 1.32 & $1.11-1.56$ \\
Hemoglobin level & $<120 \mathrm{~g} / \mathrm{L}$ & $<10^{-3}$ & 1.59 & $1.31-1.92$ \\
PB lymphocyte count & $<1 \times 10^{9} / \mathrm{L}$ & .008 & 1.27 & $1.06-1.52$ \\
LDH & $>$ ULN & $<10^{-3}$ & 1.50 & $1.26-1.77$ \\
\hline
\end{tabular}

RR indicates relative risk (of death); $\mathrm{Cl}$, confidence interval; $\mathrm{PB}$, peripheral blood $\mathrm{LDH}$, lactate dehydrogenase; and ULN, upper limit of normal.
Table 4. Results of the Cox regression analysis in 1795 patients who exhibited the 5 parameters retained for building the Follicular Lymphoma International Prognostic Index

\begin{tabular}{lccr}
\hline \multicolumn{1}{c}{ Parameter } & Adverse factor & RR & 95\% Cl \\
\hline Age & $\geq 60 \mathrm{y}$ & 2.38 & $2.04-2.78$ \\
Ann Arbor stage & III-IV & 2.00 & $1.56-2.58$ \\
Hemoglobin level & $<120 \mathrm{~g} / \mathrm{L}$ & 1.55 & $1.30-1.88$ \\
Serum LDH level & $>\mathrm{ULN}$ & 1.50 & $1.27-1.77$ \\
Number of nodal sites & $>4$ & 1.39 & $1.18-1.64$ \\
\hline
\end{tabular}

RR indicates relative risk (of death); $\mathrm{Cl}$, confidence interval; $\mathrm{LDH}$, lactate dehydrogenase; and ULN, upper limit of normal.

\section{Results}

\section{Patient characteristics}

Overall, 5120 patients from 27 centers or groups have been registered (Table 1). There were 953 who were not included for various reasons, including date of diagnosis not between 1985 and 1992 (45\%), insufficient follow-up (36\%), incomplete data $(8 \%)$, and other reasons (11\%). There were 4167 cases included in the final analysis. The median follow-up of surviving patients was 7.5 years and the overall survival of these patients is shown in Figure 2. The main clinical characteristics are shown in Table 2. Treatment modalities varied over time and according to the institutions.

\section{Univariate analysis}

The correlations between the clinical characteristics at diagnosis and overall survival are shown in Table 2. Given the size of the study population, all the listed characteristics (except cell type) were significantly associated with outcome. However, in order to propose a simple and accurate index, the clinical and statistical committees decided not to include all of these parameters in the multivariate analysis. The following parameters were not included: ESR, because this parameter was only measured in European patients, and not in those from the United States; ECOG performance status (PS), because the number of patients with a poor PS $($ ECOG $>1)$ was low $(12 \%)$ and because there was an unexplained difference in the percentage of patients with a poor PS between European (14.5\%) and US (2.1\%) centers; serum $\beta_{2}$ microglobulin level and serum albumin level because of the very high proportion of patients with missing data.

\section{Prognostic model}

Based on clinical relevance and availability of the information, 12 pretreatment characteristics were included in the multivariate

Table 5. Outcome and relative risk of death according to risk group as defined by the Follicular Lymphoma International Prognostic Index

\begin{tabular}{lcccccc}
\hline Risk group & $\begin{array}{c}\text { Number } \\
\text { of } \\
\text { factors }^{\star}\end{array}$ & $\begin{array}{c}\text { Distribution } \\
\text { of } \\
\text { patients, \% }\end{array}$ & $\begin{array}{c}\text { 5-year OS, } \\
\text { \% (SE) }\end{array}$ & $\begin{array}{c}\text { 10-year OS, } \\
\text { \% (SE) }\end{array}$ & RR & $\mathbf{9 5 \% ~ C l}$ \\
\hline Low & $0-1$ & 36 & $90.6(1.2)$ & $70.7(2.7)$ & 1.0 & NA \\
Intermediate & 2 & 37 & $77.6(1.6)$ & $50.9(2.7)$ & 2.3 & $1.9-2.8$ \\
High & $\geq 3$ & 27 & $52.5(2.3)$ & $35.5(2.8)$ & 4.3 & $3.5-5.3$ \\
\hline
\end{tabular}

$\mathrm{N}=1795$. OS indicates overall survival; $\mathrm{SE}$, standard error; $\mathrm{Cl}$, confidence interval; RR, relative risk (of death), and NA, not applicable.

${ }^{*}$ Factors adversely affecting survival in the FLIPI include age greater than 60 years; Ann Arbor stage III-IV; number of nodal sites greater than 4; serum LDH leve greater than the upper limit of normal; and hemoglobin level less than $120 \mathrm{~g} / \mathrm{L}$. 

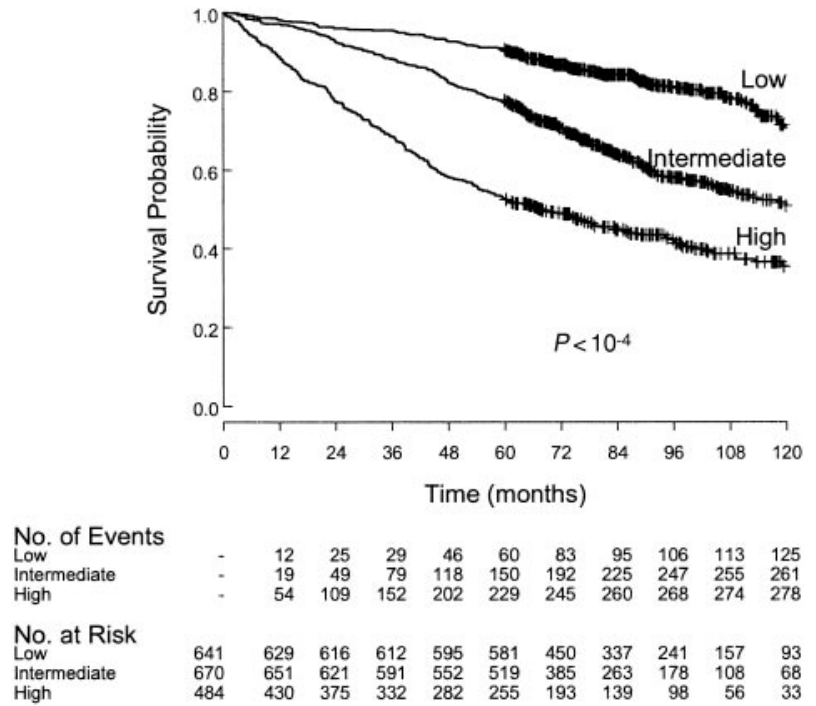

Figure 4. Survival of the 1795 patients according to risk group as defined by the Follicular Lymphoma International Prognostic Index.

analysis (sex, age group, Ann Arbor stage, bone marrow involvement, splenic involvement, number of nodal areas involved, number of extra nodal sites other than bone marrow, B symptoms, anemia, lymphocytopenia, thrombocytopenia, and serum LDH level). Both complete model and forward analyses retained 8 variables independently associated with the prognosis in a model established on 1795 patients (Figure 3) for whom these parameters were available (Table 3 ).

\section{Prognostic index}

This sample of 1795 patients comprised the population used to build the FLIPI. Both methods retained the same 5-variable submodel: age ( $\geq 60$ years vs $<60$ years), Ann Arbor stage (III-IV vs I-II), hemoglobin level ( $<120 \mathrm{~g} / \mathrm{L}$ vs $\geq 120 \mathrm{~g} / \mathrm{L})$, number of nodal areas involved ( $>4$ vs $\leq 4$ ), serum LDH level (above normal vs normal or below; Table 4). In the 100 resamples of the original data set, this 5-parameter model was classified 24 times with the best score and 59 times as one of the 3 highest scoring models. In terms of individual prediction, this model was also the closest, as measured by the D coefficient, ${ }^{26}$ to the 8 -parameter model.

Patients with a score of 5 were combined with patients with a score of 4 because the former were too rare to constitute a category. Patients with scores of 0 and 1 were combined because both correspond to a group with a very good prognosis. Combining patients with a score of 3 with those having a score of 4 or 5 yielded the smallest log-likelihood change. The FLIPI index was thus created with 3 risk groups: low (0-1 risk factor), intermediate (2 risk factors), high ( $\geq 3$ risk factors). The distribution of patients into these 3 groups and hazard ratios are shown in Table 5. The survival curves are shown in Figure 4.

\section{Comparison with the International Prognostic Index (IPI)}

This comparison was performed on 1647 of 1795 patients used for building the FLIPI for whom complete information was also available for the parameters of the IPI (age, serum LDH level, performance status, Ann Arbor stage, number of extra nodal sites of disease).

The distribution of patients into the 4 IPI risk groups and the relative risks of death are shown in Table 6. The IPI separates the patients into 4 risk groups with significantly different survivals. Meanwhile, the number of patients in "high" and "high-intermediate" risk groups is low $(4.7 \%$ and $15.5 \%$, respectively). Conversely, most of the patients are in the "low" and "low-intermediate" risk groups (49\% and 31\%, respectively). As shown in Figure 5, the FLIPI was discriminant as well as in patients with low risk $(P=.001)$, intermediate risk $(P=.001)$, and high-intermediate and high-risk $(P=.014)$ according to the IPI.

\section{Age-adjusted model}

The FLIPI was also tested in patients younger than 60 years and in patients 60 years or older. As in the IPI study, ${ }^{2}$ the 4 risk factors other than age were tested within each age group. The 4 other identified risk factors (number of nodal sites, Ann Arbor stage, serum LDH level, and hemoglobin level) remained independent prognostic factors. Survival curves for these 2 age groups are shown in Figure 6.

\section{External validation}

The data of 1101 other cases of patients with FL were received from 10 groups or centers in the United States and Europe. Of these, 92 were not analyzed because of missing values and/or inconsistencies. Overall, 919 cases $(83.5 \%)$ were included in the analysis. The median follow-up was 6.8 years. The distribution of the 5 parameters of the FLIPI among these 919 patients, the distribution among the 3 FLIPI groups, and the hazard ratios are shown in Table 7. Survival curves are shown in Figure 7.

Serum $\beta_{2}$ microglobulin $\left(\beta_{2} M\right)$ level was measured in a greater number of cases $(65 \%)$ at the time of diagnosis for this group of patients and thus could be studied as a factor that could potentially add information to the FLIPI. Serum $\beta_{2}$ M was normal in $65 \%$ of patients and increased above the upper limit of normal in $35 \%$ of patients. Survival curve analysis showed that there was no difference between patients with normal $\beta_{2}$ M or increased $\beta_{2} M$ within each FLIPI subgroup (data not shown).

Table 6. Outcome and relative risk of death according to risk group as defined by the IPI among the 1647 patients for whom data for the FLIPI and the IPI were available

\begin{tabular}{|c|c|c|c|c|c|c|}
\hline Risk group & $\begin{array}{c}\text { Number of } \\
\text { factors }\end{array}$ & $\begin{array}{c}\text { Distribution of } \\
\text { patients, } \%\end{array}$ & $\begin{array}{c}\text { 5-year OS, \% } \\
\text { (SE) }\end{array}$ & $\begin{array}{c}\text { 10-year OS, \% } \\
\text { (SE) }\end{array}$ & $\mathbf{R R}$ & $95 \% \mathrm{Cl}$ \\
\hline Low & $0-1$ & 49 & $88.1(1.1)$ & $67.3(2.5)$ & 1.0 & NA \\
\hline Low-intermediate & 2 & 31 & $70.9(2.0)$ & $49.5(2.8)$ & 2.2 & $1.8-2.7$ \\
\hline High-intermediate & 3 & 15 & $57.4(3.1)$ & $27.6(4.1)$ & 3.5 & $2.8-4.3$ \\
\hline High & $4-5$ & 5 & $43.6(5.6)$ & $35.8(5.6)$ & 4.5 & $3.3-6.2$ \\
\hline
\end{tabular}

OS indicates overall survival; SE, standard error; Cl, confidence interval; RR, relative risk (of death); and NA, not applicable.

${ }^{*}$ Factors adversely affecting survival in the IPI ${ }^{2}$ include performance status greater than 1 ; number of extra nodal sites greater than 1 ; serum LDH level greater than the upper limit of normal; Ann Arbor stage III-IV; and age greater than 60 years. 
A

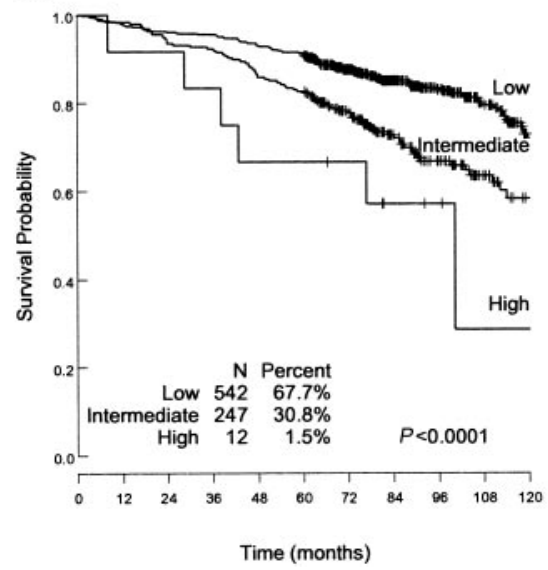

B

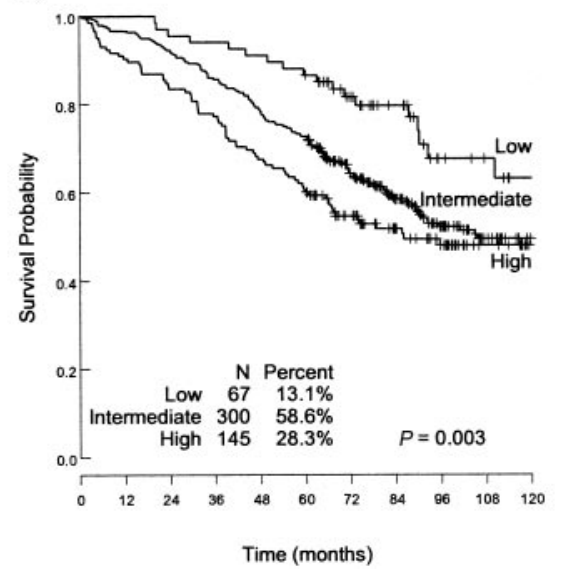

C

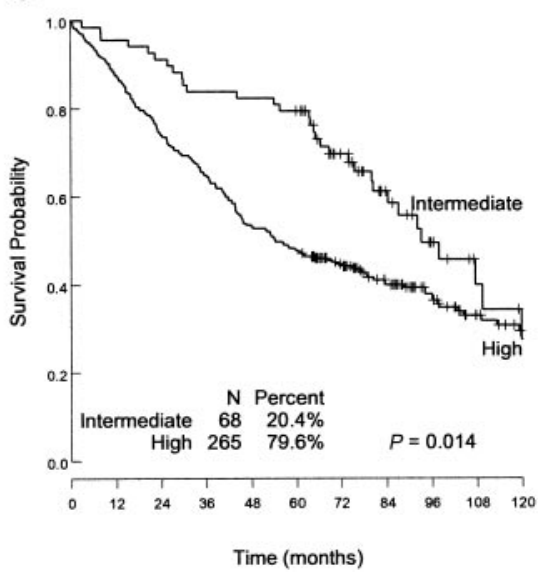

Figure 5. Overall survival of patients with low IPI risk, low-intermediate IPI risk, and high-intermediate plus high IPI risk as determined by the Follicular Lymphoma International Prognostic Index (FLIPI). (A) Low IPI risk. (B) Low-intermediate IPI risk. (C) High-intermediate and high IPI risk. Within each IPI risk group, the FLIPI can discriminate patients in groups with significantly different death risks.

\section{Discussion}

Among all NHLs, follicular lymphomas are the second most frequent subtype. Unfortunately, there is no truly effective therapy for FL, and its prognosis has remained basically unchanged over the last 30 years. ${ }^{1}$ However, several new treatment modalities including combination of chemotherapy and interferon alpha, ${ }^{27}$ anti-CD20 monoclonal antibodies given alone ${ }^{28}$ or bound to a radio nuclide, ${ }^{29}$ intensive therapy with autologous stem cell transplantation, ${ }^{30}$ or nonmyeloablative allogenic stem cell transplantation ${ }^{31}$ have recently shown their activity in clinical trials. These treatments have significant toxicities and are costly. To better define the patients in whom these therapies are warranted, a prognostic index would be very helpful.

From a large and multicentric database of patients, we were able to propose and to validate a prognostic index for follicular lymphomas, the FLIPI. Although inclusion criteria did not define

\section{A}

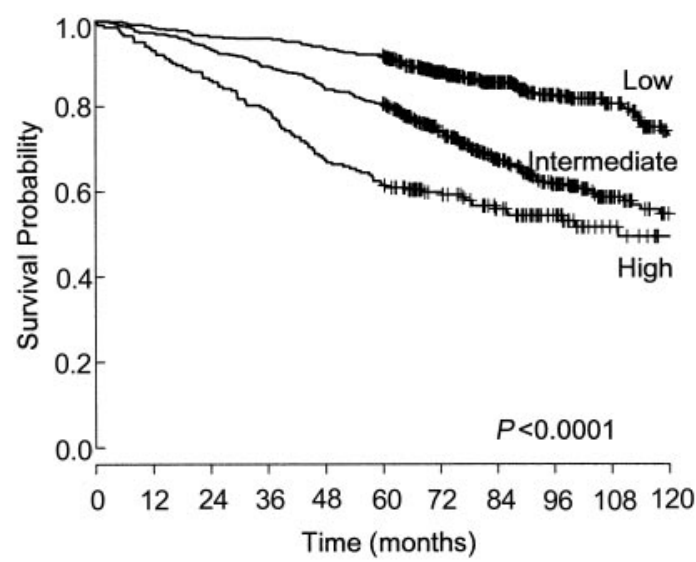

No. of Events
Low
Intermediate
High
No. at Risk
Low
Intermediate
High


- $\quad \begin{array}{llllllllll}13 & 32 & 51 & 77 & 93 & 121 & 144 & 159 & 164 & 168\end{array}$ $\begin{array}{llllllllll}14 & 28 & 42 & 66 & 78 & 81 & 87 & 89 & 91 & 92\end{array}$

$524515504502490481368271 \quad 191 \quad 130 \quad 78$ $\begin{array}{llllllllllll}478 & 465 & 446 & 427 & 401 & 384 & 290 & 196 & 130 & 75 & 48\end{array}$

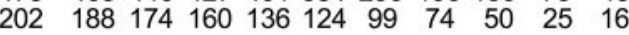

age limits, the median age was 56 years with $37 \%$ of patients older than 60 years. This median age, possibly lower than that of all patients with FL, may be related to the fact that most patients were registered by groups and included in clinical trials (Table 1). However, this has probably no influence on results. This index includes parameters related to patient characteristics (age), tumor burden (Ann Arbor stage, number of nodal sites), tumor aggressiveness (serum LDH level), and consequences of the lymphoma on the host (hemoglobin level). Using this index, 3 risk groups of approximately the same size $(36 \%, 37 \%$, and $27 \%)$ have been separated. There is clearly a difference in survival between each of these risk groups. An external validation on another group of 919 patients with FL showed a very similar distribution of patients, highly significant differences in overall survival, and similar hazard ratios between the 3 FLIPI subgroups. This external validation confirms the reproducibility of the FLIPI analysis.

All the parameters of the FLIPI have been found to significantly influence prognosis in several other analyses ${ }^{3-20}$ and have been included

\section{B}
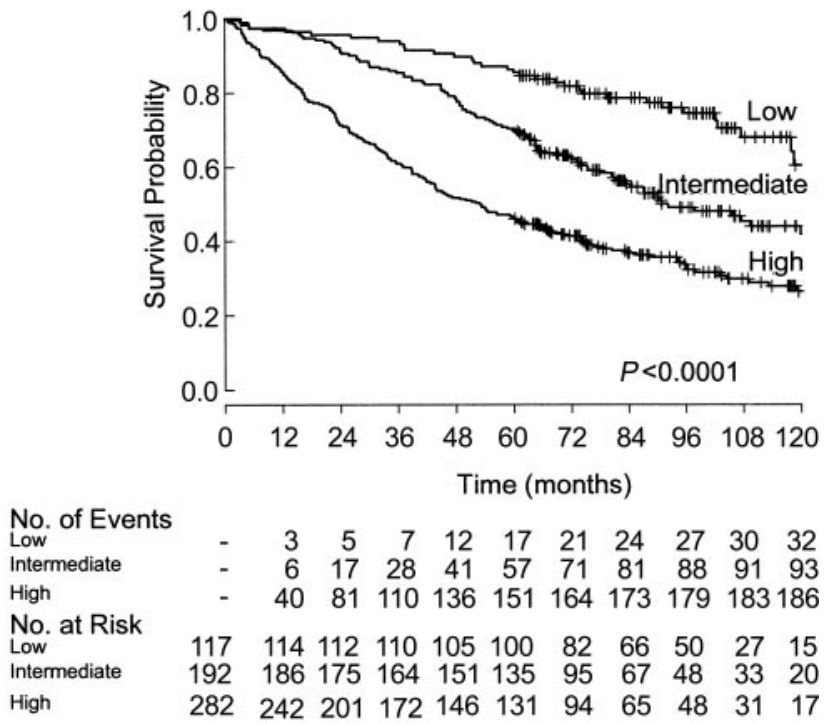

Figure 6. Survival of 1795 patients according to risk group as defined by the Follicular Lymphoma International Prognostic Index. Patients younger than 60 years (A); patients 60 years or older $(B)$. 
Table 7. Characteristics of the patients studied for the "external" validation of the Follicular Lymphoma International

Prognostic Index (FLIPI)

\begin{tabular}{lc}
\hline \multicolumn{1}{c}{ Characteristic } & Number of patients (\%) \\
\hline Age & \\
Younger than $60 \mathrm{y}$ & $626(68)$ \\
60 y or older & $293(32)$ \\
$\begin{array}{l}\text { Ann Arbor stage } \\
\text { I-II }\end{array}$ & $191(21)$ \\
III-IV & $729(79)$ \\
LDH & \\
Less than or equal to ULN & $709(77)$ \\
Greater than ULN & $210(23)$ \\
Hemoglobin level & \\
Less than 120 g/L & $178(19)$ \\
Greater than or equal to $120 \mathrm{~g} / \mathrm{L}$ & $741(81)$ \\
Number of nodal sites & \\
Less than or equal to 4 & $568(62)$ \\
Greater than 5 & $351(38)$ \\
FLIPI & \\
Low & $345(38)$ \\
Intermediate† & $320(35)$ \\
High $\ddagger$ & $254(28)$ \\
\hline
\end{tabular}

$\mathrm{N}=919$ patients. LDH indicates lactate dehydrogenase; and ULN, upper limit of normal.

${ }^{*}$ Relative risk of death: 1.

tRelative risk of death $(95 \% \mathrm{Cl}): 2.45(1.75-3.41)$

fRelative risk of death $(95 \% \mathrm{Cl}): 4.68(3.39-6.46)$.

in other prognostic indices. $3,4,9,12$ These parameters have been routinely evaluated in the initial staging of patients with FL for many years. This will allow the comparison of the distribution of patients and the survival curves of many other series' with those reported herein and will further evaluate the accuracy of the FLIPI. Treatment was not included in the prognostic analysis, which concerned only initial characteristics. However, although treatments were heterogeneous, none of the treatments given during the period of inclusion has significantly changed the natural history of the disease. ${ }^{1}$

The number of prognostic factors used to build this index was deliberately limited in order to obtain a simple and accurate index. The concordance in discriminatory power between the training and confirmation groups demonstrates the accuracy of the FLIPI. An additional advantage of the FLIPI is that it can be used irrespective of age group.

The FLIPI may be used for selecting treatment in individual patients. In patients with a good prognosis (0-1 adverse factor), the 10 -year overall survival is $71 \%$. This indicates that optimal treatment in these patients has to avoid toxicity and to preserve quality of life. Involved-field radiation therapy for patients with limited disease and an initial "no treatment policy," for patients with disseminated disease may be recommended outside clinical trials. In contrast, patients with high-risk FL have a median survival around 5 years. Innovative approaches such as the combination of CVP (cyclophosphamide, vincristine, prednisone) or CHOP (CVP

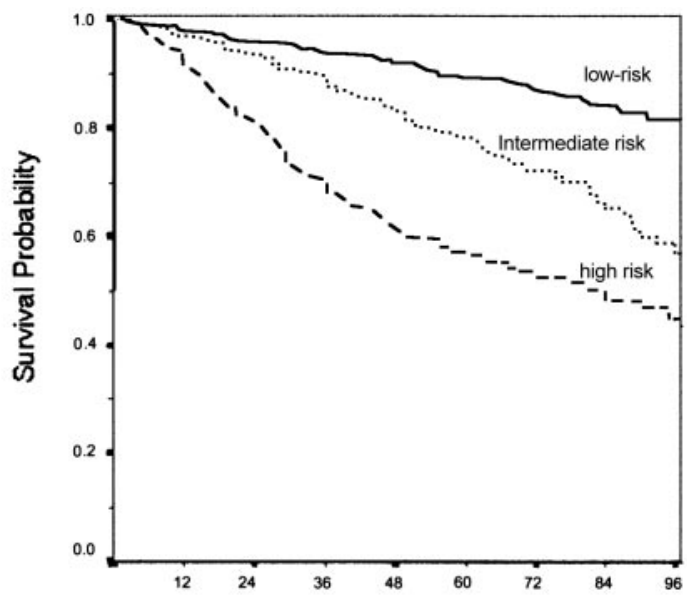

Time (months)
No. Of

Events

Low-risk

Intermediate-risk

High-risk

Low-risk

Intermediate-risk

High-risk
Figure 7. Overall survival of the 919 patients used for validation of the Follicular Lymphoma International Prognostic Index. Solid line indicates patients in the low-risk group (0-1 factor); dotted line, patients in the intermediate-risk group (2 factors); dashed line, patients in the high-risk group ( $\geq 3$ factors). $P<10^{-4}$.

plus doxorubicin) and anti-CD20 monoclonal antibody, ${ }^{32}$ purine analog-based regimens, ${ }^{33}$ and autologous stem cell transplantation $^{30}$ followed by vaccine therapies ${ }^{34}$ may be studied in this subgroup. All these approaches have been so far evaluated in phase 2 studies. The size of the high-risk group (27\% of patients in the sample used for creating this index and $28 \%$ in the sample used for validation) could allow the design of multicenter randomized trials.

In conclusion, the FLIPI is an extremely simple and reproducible prognostic index, based on easily available clinical data, for patients with FL. This index may be a useful tool for improving the prognostic assessment of patients with FL. It can also be of help in selecting the most appropriate treatment in individual patients and in stratifying patients in prospective trials.

\section{Acknowledgments}

The authors would like to acknowledge the following people who participated in the study (alphabetical order): A. Altès, M. Bast, P. Biermann, A. Bosly, M. Caniard, F. Cavalli, J. Estève, M. Ferrandon, G. Follea, D. Harrington, M. Hess, S. Houga, R. Liang, C. Linassier, R. M. Livet, J. Matthews, N. Milpied, R. J. Prescott, L. Remontet, F. Reyes, B. Riche, J. Vose, and H. Wotherspoon.

\section{References}

1. Horning ST. Natural history of and therapy for the indolent non-Hodgkin's lymphomas. Semin Oncol. 1993;20:75-80.

2. The International Non-Hodgkin's Lymphoma Prognostic Factors Project. A predictive model for aggressive non-Hodgkin's lymphoma. N Engl J Med. 1993;329:987-994.

3. Decaudin D, Lepage E, Brousse N, et al. Lowgrade stage III-IV follicular lymphoma: multivariate analysis of prognostic factors in $484 \mathrm{pa}$ - tients: a study of the Groupe d'Etude des Lymphomes de l'Adulte. J Clin Oncol. 1999;17: 2499-2505.

4. Leonard RCF, Hayward RL, Prescott RJ, et al. The identification of discrete prognostic groups in low-grade non-Hodgkin's lymphoma: The Scotland and Newcastle Lymphoma Group Therapy Working Party. Ann Oncol. 1991;2: 655-662.

5. Cameron DA, Leonard RCF, Mao J-H, et al.
Identification of prognostic groups in follicular lymphoma. Leuk Lymphoma. 1993;10:89 99.

6. Gospodarowicz MK, Bush RS, Brown TC, et al. Prognostic factors in nodular lymphomas: a multivariate analysis based on the Princess Margaret Hospital experience. Int J Radiat Oncol Biol Phys. 1994;10:489-492.

7. Denham JW, Denham E, Dear KB, et al. The follicular non-Hodgkin's lymphomas, II: prognostic 
factors: what do they mean? Eur J Cancer. 1996; 32A:480-490.

8. Soubeyran P, Eghbali H, Bonichon F, et al. Lowgrade follicular lymphomas: analysis of prognosis in a series of 281 patients. Eur J Cancer. 1991; 27:1606-1613

9. Federico M, Vitolo U, Zinzani PL, et al. Prognosis of follicular lymphoma: a predictive model based on a retrospective analysis of 987 cases. Blood. 2000;95:783-789.

10. Maartense E, Le Cessie S, Kluin-Nelemans HC, et al. Age-related differences among patients with follicular lymphoma and the importance of prognostic scoring systems: analysis from a population-based non-Hodgkin's lymphoma registry. Ann Oncol. 2002;13:1275-1284

11. Steward WF, Crowther D, McWilliam LJ, et al. Maintenance chlorambucil after CVP in the management of advanced stage, low-grade histologic type non-Hodgkin's lymphoma. Cancer. 1988;61: 441-447.

12. Romaguera JE, McLaughlin $P$, North $L$, et al. Multivariate analysis of prognostic factors in stage IV follicular low-grade lymphoma: a risk model. J Clin Oncol. 1991;9:762-769.

13. Bastion $\mathrm{Y}$, Berger F, Bryon PA, et al. Follicular lymphomas: assessment of prognostic factors in 127 patients followed for 10 years. Ann Oncol. 1991;2(suppl 2):123-134.

14. Litam P, Swan F, Cabanillas F, et al. Prognostic value of serum beta-2 microglobulin in low-grade lymphoma. Am J Med. 1991;114:855-860.

15. Coiffier B, Bastion Y, Berger F, et al. Prognostic factors in follicular lymphomas. Semin Oncol. 1993;5(suppl 5):89-95

16. Hermans J, Krol ADG, van Groningen K, et al. International Prognostic Index for aggressive
non-Hodgkin's lymphoma is valid for all malignancy grades. Blood. 1995;86:1460-1463.

17. Lopez-Guillermo A, Montserrat E, Bosch F, et al. Applicability of the International Prognostic Index for aggressive lymphomas to patients with lowgrade lymphoma. J Clin Oncol. 1994;12:13431348.

18. Avilès A. The International Index is not useful in the classification of low-grade lymphoma. J Clin Oncol. 1994;12:2766-2770.

19. Bastion $Y$, Coiffier $B$. Is the International Prognostic Index for aggressive lymphoma patients useful for follicular lymphoma patients? J Clin Oncol. 1994;12:1340-1342.

20. Foussard C, Desablens B, Sensebe L, et al. Is the International Prognostic Index for aggressive lymphomas useful for low-grade lymphoma patients? applicability to stage III-IV patients. Ann Oncol. 1997;8(suppl 1):S49-S52.

21. Non-Hodgkin's Lymphoma Pathologic Classification Project. A National Cancer Institute-sponsored study of classifications of non-Hodgkin's lymphomas: summary and description of a working formulation for clinical usage. Cancer. 1982; 49:2112-2135.

22. Stansfeld AG, Diebold AJ, Noel H, et al. Updated Kiel classification for lymphomas. Lancet. 1988;1: 292-293.

23. Kaplan EL, Meier P. Nonparametric estimation from incomplete observations. J Am Stat Assoc. 1958:53:457-481.

24. Royston P. A strategy for modeling the effect of a continuous covariate in medicine. Stat Med. 2000;30:1831-1847.

25. Cox DR. Regression models and life tables. JR Stat Soc. 1972;34:187-220.

26. Harrell FE, Lee KL, Mark DB. Multivariable prognostic models: issues in developing models, evaluating assumptions and adequacy, and measuring and reducing errors. Stat Med. 1996;15: 361-387.

27. Solal-Céligny $P$, Lepage $E$, Brousse $N$, et al. Doxorubicin containing regimen with or without interferon alfa-2b for advanced follicular lymphomas: final analysis of survival and toxicity in the Groupe d'Etude des Lymphomes Folliculaires 86 trial. J Clin Oncol. 1998;16:2332-2338.

28. McLaughlin P, Grillo-Lopez AJ, White CA, et al. IDEC-C2B8 (rituximab) anti-CD20 monoclonal antibody therapy for relapsed indolent B-cell lymphoma: half of the patients respond to a fourdose treatment program. J Clin Oncol. 1998;16: 2825-2833.

29. Dillman RO. Radiolabeleded anti-CD20 monoclonal antibodies for the treatment of B-cell lymphoma. J Clin Oncol. 2002;20:3545-3557.

30. Hunault-Berger M, Ifrah N, Solal-Céligny P. Intensive therapies in follicular non-Hodgkin lymphomas. Blood. 2002;100:1141-1152.

31. Khouri IF, Saliba RM, Giralt SA, et al. Non-ablative allogeneic hematopoietic transplantation as adoptive immunotherapy for indolent lymphoma: low incidence of toxicity, acute graft-versus-host disease and treatment-related mortality. Blood. 2001:98:3584-3588.

32. Czuczman M, Grillo-Lopez AJ, White CA, et al. Treatment of patients with low-grade B-cell lymphoma with the combination of chimeric antiCD20 monoclonal antibody and CHOP chemotherapy. J Clin Oncol. 1999;17:268-276.

33. Flinn IW, Byrd JC, Morrison C, et al. Fludarabine and cyclophosphamide with filgrastim support in patients with previously untreated indolent lymphoid malignancies. Blood. 2000;96:71-75.

34. Schultze J, Nadler LM. T-cell mediated immunotherapy for B-cell lymphoma. J Mol Med. 1999; 77:322-331. 